\title{
أساليب القرآن للفراهي والموازنة بينه وبين البرهان في علوم القرآن للزركشي
}

\section{A COMPARATIVE STUDY BETWEEN ASĀLÎB AL-QURĀN BY 'ABD AL- HAMÎD AL-FARĀHI AND AL-BURHĀN FÎ 'ULŪM AL-QURĀN BY AL- ZARKASYî}

\author{
Mohd Farid Ravi Abdullah \\ Kolej Universiti Islam Antarabangsa Selangor (KUIS), Malaysia \\ Email: faridravi@kuis.edu.my
}

\author{
Abur Hamdi Usman \\ Kolej Universiti Islam Antarabangsa Selangor (KUIS), Malaysia \\ Email: aburhamdi@kuis.edu.my
}

\begin{tabular}{|c|c|}
\hline 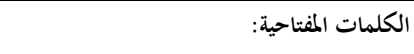 & المستلخص \\
\hline أساليب، مقارنة، نظام القرءان، الزركشيُّ، الفراهيُ. & 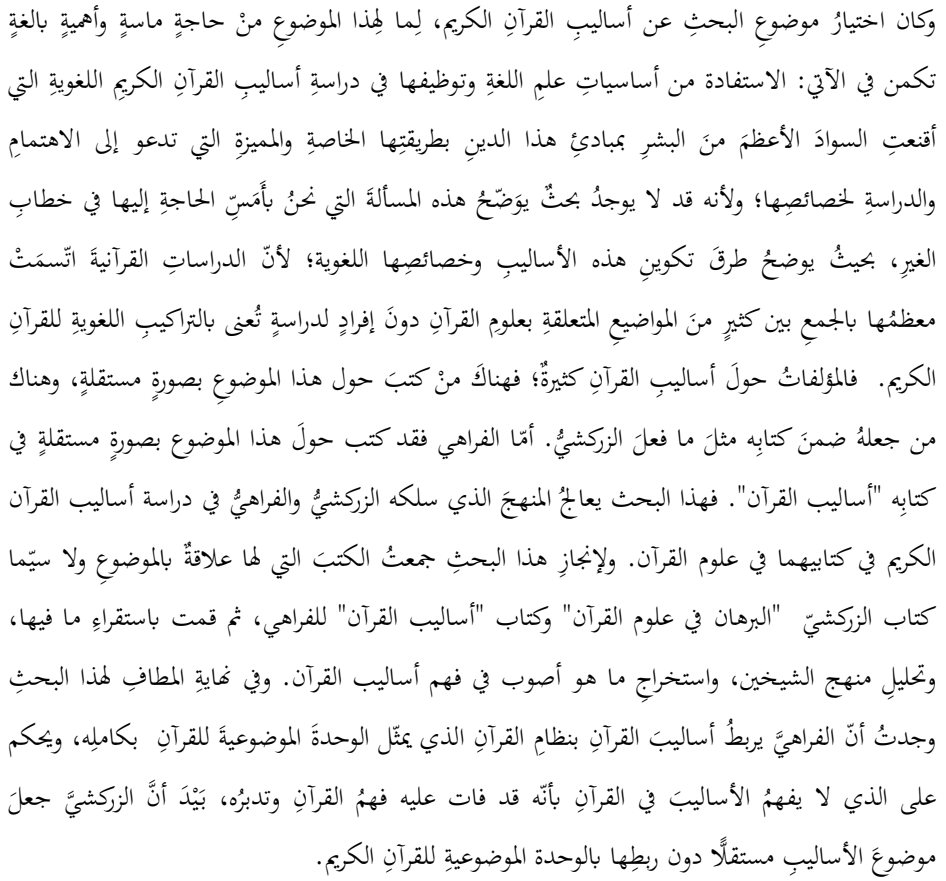 \\
\hline Kata kunci : & ABSTRACT \\
\hline $\begin{array}{l}\text { Stylistic, Comparative, Coherence, } \\
\text { al-Farahī, al-Zarkashī }\end{array}$ & $\begin{array}{l}\text { This study focused on the techniques of the Qur'an, which is particularly } \\
\text { selected due to the vital importance of making use of the linguistic } \\
\text { techniques and employing them in studying the linguistic techniques of } \\
\text { the Qur'an which have convinced the majority of people to accept the } \\
\text { principles of this religion, Islam, through their distinctive features which } \\
\text { call attention to their research. Besides, there is a lack of studies which } \\
\text { investigated and explained the formation and structures of the } \\
\text { techniques of the Qur'an, the techniques we are in dire need of to } \\
\text { address others. It is noticed that the previous Qur'anic studies have been }\end{array}$ \\
\hline
\end{tabular}


Website: https://journal.stiba.ac.id ISSN : 2685-7537 (online); 2338-5251 (Printed)

more concerned with focusing many topics related to the sciences of the Qur'an but no study has examined the linguistic structures of the Qur'an. Much research has studied the techniques of the Qur'an; for instances some researchers investigated this topic independently such as al-Farahi in his book Asā lib al-Qurān while others, like al-Zarkashī, just discussed it in part of his book, al-Burhān Fì 'Ulūm al-Qurān. Therefore, the present study investigates the approaches used by al-Zarkshahi and alFarahi in studying the techniques of the Qur'an in their books related to the sciences of the Qur'an. To achieve the objectives of this study, the books related to the topic are collected and examined. Moreover, the approaches employed by al-Zarkashì and al-Farahì are analyzed and then the useful techniques which could be utilized for understanding the Qur'an are also identified. The findings of the study reveal that al-Farahi links the techniques of the Qur'an with the coherence of the Qur'an, which represents the objective unity of the whole Qur'an. It is also shown that al-Farahi believes that those who do not understand the techniques of the Qur'an have missed the understanding of and the reflection on the Qur'an. However, it is revealed that al-Zarkashì makes the linguistic techniques independent from the objective unity of the Qur'an.

Diterima: 20 Juni 2020; Direvisi: 27 November 2020; Disetujui: 27 November 2020; Tersedia online: 18 Desember 2020.

How to cite : Abdullah, M. F. R. \& Usman, A. H. (2020). أساليب القرآن للفراهي والموازنة بينه وبين البرهان في علوم القرآن للزركشي/2). NUKHBATUL 'ULUM: Jurnal Bidang Kajian Islam, 6 (2), 258-272. https://doi.org/10.36701/nukhbah.v6i2.157

المقدمة

فإن لعلم التفسير منزلة عظيمة ومكانة عالية بين العلوم الشرعية، نظرا ذلك فقد قام العلماء بخدمة هذا العلم من شتى نواحيه في كل مصر وعصر، ووقفوا لذلك حياتم، منهم: المفسر الأديب، العلامة الجليل، المؤلف المكثر، الإمام أبو أحمد عبد الحميد بن عبد المحسن الأنصاري الفراهي الذي كان يجمع بين التبحر في العلوم العربية والدينية، ومؤلفاته تبلغ واحدا وخمسين كتابا ومن تلك الكتب وأعظمها ما كتبه حول القرآن الكريم و تأويله وتفسيره، وفصاحته وبلاغته، ومفرداته، وكل ما يتصل به من العلوم القرآنية. فمن أهداف هذا البحث، إنه يسلط الضوء على دور علماء الهند في خدمة القرءان الكريم ويبرز أحد مؤلفات الفراهي في القرآن الكريم ألا وهو أساليب القرآن والمقارنة بالبرهان في علوم القرآن للزركشي لنعرف أيهما أحسن في كتابة موضوع أساليب القرآن؟ وأما منهج الذي اعتمدت عليه هو المنهج الاستقرائي والمنهج النقدي ومنهج المقارنة بالموازنة بين آراء الفراهي في أساليب القرآن و الزركشي في كتابه علوم القرآن. ولإنجاز هذا البحث تتبعت ببعض الدراسات 
السابقة التي لما علاقة بهذا الموضوع، فمنها: جهود العلماء الهنود في تفسير القرآن الكريع في القرن الرابع عشر الهجري، للباحث محمد عزير بن عبد المعين، ففي هذا البحث ذكر الباحث الفراهي

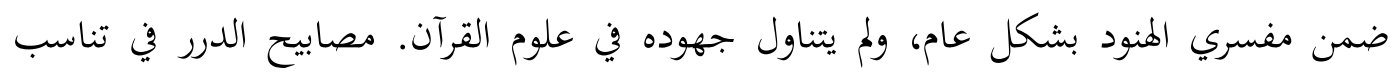
آيات القرآن الكريم والسور، و ذكر الباحث في هذا البحث آراء الفراهي في علم المناسبة. حميد الدين الفراهي: حياته ومنهجه في تفسير القرآن وأثر ذلك في الهند، للباحث سيد سعيد أحسن العابدي، وهي رسالة الدكتوراه التي قدمها الباحث إلى جامعة الأزهر عام 1971م. ولم يقم الباحث بالمقارنة منهج الفراهي بغيره خاصة في علوم القرآن. مناسبات الآيات والسور: للأستاذ الدكتور أحمد حسن فرحات، وهو بحث منشور في مجلة الجامعة الإسلامية، بالمدينة المنورة في عددها لعام 2010م وفي الاتحاه الرابع تكلم عن منهج الفراهي في النظام هو جزء من المناسبات بين الآيات والسور في القرآن. فهذه بعض ما قرأت من الدراسات السابقة في خدمة الفراهي في التفسير وعلوم القرآن وأما أساليب القرآن للفراهي لم يدرس فيه أحد لاسيما المقارنة والموازنة في أساليب القرآن للفراهي بغيره. والمقصود بنظمه طريقة تأليف حروفه، وكلماته، وبمله، وتناسقها، وسبكها مع أخواتما في قالب

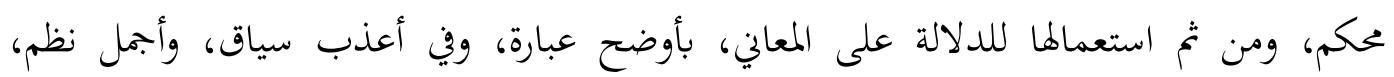
والعرب وهم الفصحاء وهم أهل البلاغة والبيان قد بهرهم القرآن في نظمه، وسياق لفظه في كل خبر، وصورة كل عظة، وبهرهم أغم تأملوه سورة سورة، وعشراً عشراً، وآية آية، فلم يجدوا إلا التناسق في التعبير، والتصوير وقوة التأثير الذي بهر العقول وأعجز الجمهور، ووجدوا إتقاناً وإحكاماً فلم تستطع العرب أن تأني بمثله ولو كان بعضهم على بعض ظهيرا، حتى خرست الألسن عن أن تدعى وتتقول . فأسلوب القرآن مؤثر على العامة والخاصة، يقرؤه العالم فيدرك خصائصه وبلاغته، ويؤثر فيه بيانه، ودقة علومه ومعارفه ،ويقرؤه العامي فيشعر بجلاله، وحلاوته، فيخشع قلبه، وتدمع عينه،

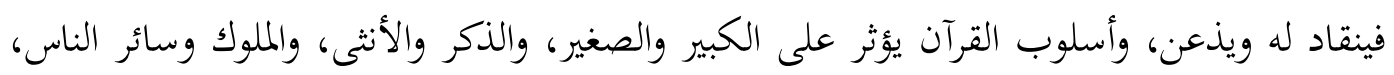
وهذا لا يكون إلا في القرآن العظيم بأسلوبه المؤثر في كل زمان وكل مكان . 
المطلب الأول:توجمة الفراهي والتعريف بكتابه "أساليب القرآن" هو عبد الحميد بن عبد الكريم بن قربان قنبر بن تاج علي، حميد الدين، ولد الفراهي في قرية فريها، صباح يوم الأربعاء، سادس جماد الآخر، سنة 1280هـ. توفي الفراهي وهو يتلو القرآن

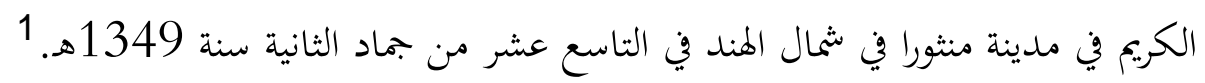
كتاب "أساليب القرآن" واحد من الكتب التي ألفها الإمام الفراهي في علوم القرآن، ولا يصلح أن يعد هذا الكتاب من تصانيفه الناقصة كما يظنه بعض الباحثين؛ لأن التصفح في هذا الكتاب يدل دلالةً واضحةً على أن الفراهي كان قد جمع إثارات وتلميحات وملاحظات في هذا الموضوع، ولكن لم تتح له فرصة لتسويدها، ولما توفي كرحه الله- جُمعت هذه المواد العلمية والتلميحات النافعة، ونُشرت في كتاب.

وكان الفراهي سمى هذا الكتابَ بـ"كتاب الأساليب" بدلاً بـ"أساليب القرآن"؛ وذلك أنه ليس من قصده أن يخصه بالقرآن الكريم فحسب، بل كان يريد أن يكون أساس وضعه على أساليب كلام العرب، كما يقول: "هذا الكتاب ليس ككتاب المفردات مختصاً بالقرآن، ولكنه ئه متضمن لفن برأسه، يجري حكمه في عموم أساليب كلام العرب، غير ما اختص بالقرآن لكونه منزلاً

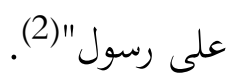
وأقرب ما يمكن أن هذا الاسم كان مذكوراً في مسودته، ويؤيد ذلك أن هذا الكتاب قبل الطبع كان مشهوراً على الألسن بكتاب الأساليب، وذكره الأستاذ أمين أحس الإصلاحي في رسالة مطبوعة دورية بهذا الاسم، حيث قال: "كتاب الأساليب وأصول التأويل في صدد الطبع، وسيطبعان في أقرب وقت إن شاء الله"(3).

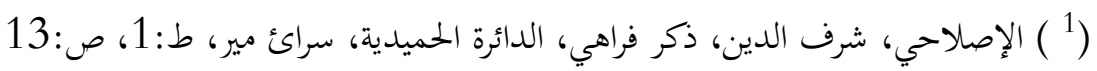

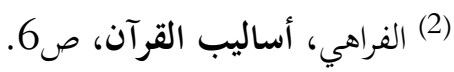

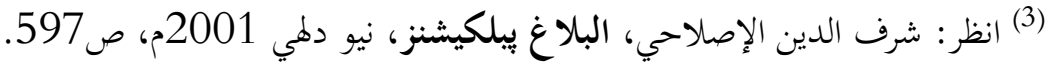


وذكره أيضاً في مقدمة تفسيره "تدبر القرآن" بهذا الاسم حيث قال: "تنكشف بمطالعة القرآن الكريم، وأدب زمان نزول القرآن، أصول الحذف والإيباز العديدة، رتبها أستاذي مولانا الفراهي وجمعها في كتاب له كتاب الأساليب"(4). ولا غرو أن الفراهي عندما يحتاج في أي كتاب من كتبه إلى ذكر مرجع هذا الكتاب فلعله أشار إلى هذا الاسم، إذ كان من قصده أن يكون أساس الكتاب على كلام العرب، لذلك سماه "كتاب الأساليب" ولم يسمه "أساليب القرآن"، ولكنه لم يستوعب هذا الموضوع، وكثيراً ما كتب في المسودة ما يتعلق بالقرآن الكريم، وما وجد من الأمثلة المتنوعة في أبواب متعددة وفصول مختلفة فهو مستقطب من آيات القرآن، بيد أن هناك أمثلة قليلة مأخوذة من كلام العرب، ولأجل ذلك قد تقرر عندي أن هذا الكتاب صار مسميَّ ب"أساليب القرآن" بعد، لئلا يختلف الاسم والمسمى، ولئلا يتباعد العنوان والألوان، وقد نسب الأستاذ أمين أحسن الإصلاحي هذا الاسم إلى هذا الكتاب(5) وسببه واضح جلي، وأيضاً أشار العلامة سليمان الندوي إلى هذا الاسم في ذيول كتابه "إمعان في

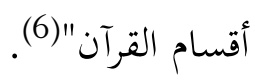

إن قصد الفراهي من خلال ما ألَّفه من الكتب في التفسير أو في فن آخر، لا يكون إلا تعبيد الطريق وتمهيد السبيل إلى فهم القرآن الكريم، وكما ختم الأستاذ كثيراً من الأمور المذكورة في كتابه لفهم القرآن، كذلك قد ألزم التطلع الواسع العميق على أساليب اللغة العربية وأساليب القرآن الكريم، ومراده هنا باللغة الأدب العربي الذي نشأ وترعرع في زمان نزول الوحي، ومن هذه الناحية لم يعتبر لغة المولدين لغةً يستند إليها أو يوثق بها، حيث يقول عن غاية هذا الكتاب، ما نصه: كما أن المقصود من كتاب المفردات إحاطة العلم حتى الوسع بدلالة الكلم بحرمه ووجوهه، وكذلك المقصود من هذا الكتاب إحاطة العلم حتى الوسع بدلالات الصور والأساليب ومواقع استعمالها، فإن حض العلم بأسلوب خاص من دون تخصيص مواقعه، يفتح باباً عظيماً لسوء التأويل، مثلاً قالوا: إن كلمة

$$
\begin{aligned}
& \text { (4) أمين الإصلاحي، مقدمة تدبر قرآن، فاران فونديشن، لاهور، ط1، 2009م، ج1، ص23. }
\end{aligned}
$$

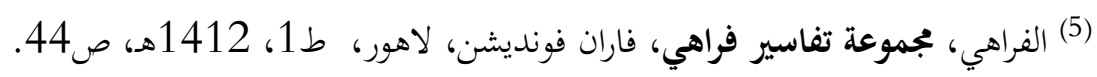

$$
\begin{aligned}
& \text { (6) انظر ذيل كتاب "إمعان في أقسام القرآن، ترجمة صاحب هذه هواسير الرسالة. }
\end{aligned}
$$


"لا" بما تأتي زائدة، فإهمال هذا القول أقرب إلى الضرر منه إلى النفع، فإنه يجعل النفي إثباتاً، فلا بد

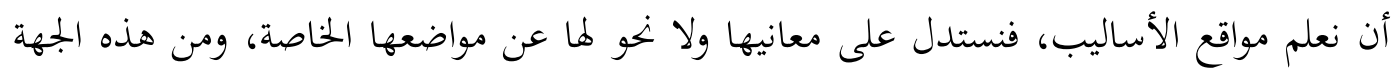

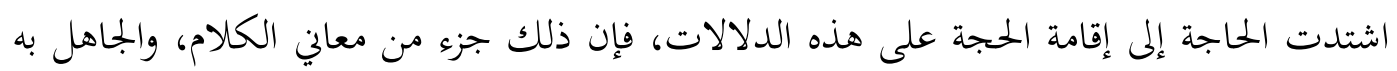
كالجاهل ببعض المعاني لكلمة مشتركة، فلا يؤوها إلا إلى ما علم من معانيه وربما يكون المراد غيره" (7).

ومما يدل على أهمية الكتاب وموضوعه ومحتوياته وما يحتله هذا الفن من مكانة عالية شاغخة التصريحات والتعليمات التي ذكرت في هذا الكتاب، ولكن الأستاذ الفراهي لم يتحدث عن أهمية هذا الفن ولم يتناول هذه النقاط إلا بإيجاز واختصار، ولو قمنا باستعراض هذه النقاط لطال الكلام ولضاق المقام، ولم يثر كذلك علماء المعاني موضوع أساليب الكلام، إلا أن الفقهاء الأصوليين اقتبسوا من هذا الموضوع بعض القواعد والمسائل حسب ما ألجأقم الضرورة إليه، ولم يستطع هذا الفن أن يركز عناية عدد من الباحثين والمحقين رغم أنه يحمل في طيه أهمية بالغة قصوى، والإمام

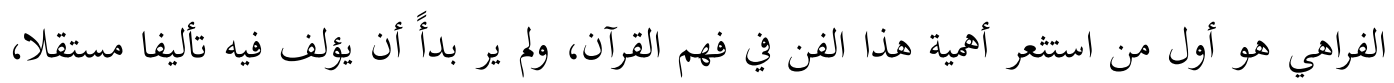
فلم يسبقه أحد في هذا الباب، والفضل في ذلك يرجع إليه، فليته أتَّهَ هذا الكتاب وفقاً لما كان تصوره، وما كان في الكتاب فهو ناقص، ورغم ذلك كله لا يمكن الجحود والإنكار بأهميته وإفادته، وهناك أمر يحتاج إلى الوضوح والبيان وهو أن من يريد المطالعة والاستفادة من هذا الكتاب فليعلم أنه ليس تأليفاً مستقلاً بل هي مجموعة من الإشارات والتلميحات، وهي تتوخى منه المعرفة التامة والاطلاع الواسع على أفكار المؤلف ونظرياته وميوله مع التفكر والتعمق والنظر فيها. وقد تطرق كلام المؤلف في هذا الكتاب إلى أساليب الكلام ومواقع استعمالها المتنوعة مصحوبة بالأمثلة القرآنية عن طريق العناوين المختلفة التي يصل عددها إلى اثنين وثلاثين بعد وضع الأبواب والفصول التمهيدية، ولا يمكن الوصول إلى المعنى المراد الصحيح إلا بمعرفة هذه الأساليب ومواقع استخدمها.

$$
\text { (7) - (7) الفراهي، أساليب القرآن، ص155. }
$$

Mohd Farid Ravi Abdullah, Abur Hamdi Usman, أساليب القرآن للفراهي... 
ومما يجدر بالذكر أن الأمثلة المختلفة كلها في هذا الكتاب مقتبسة من القرآن الكريم، غير أن هناك أمثلة عديدة مأخوذة من أساليب كلام العرب، وتناول المؤلف الجرجاني (8)، والكسائي(9)، والفراء(10)، وابن تيمية، بدراسة نقدية، وإن نظرة سريعة على عناوين الكتاب ومحتوياته تكفي لمعرفة ذكاء المؤلف، وتوقد ذهنه، وتبحر علمه، وسعة مطالعته، وآرائه القيمة، وأفكاره السديدة، فجاء ككتاب مستقل بعينه يسلط ضوءاً على أساليب القرآن، ولكن كتاب الأساليب ينتظر عناية من الباحثين والمحققين.

\section{المطلب الثاني: تعريف "البرهان في علوم القرآن" للزركشي أولاً: نبذة عن المؤلِّف}

هو محمد بن بهادر بن عبد الله، بدر الدين أبو عبد الله الزركشي (ت: 794هـ)، محيي الدين الرحماوي ويقال له "بهاء الدين زاده": فقيه متصوف من الموالي الروميّة، معمر من أهل "بالي كسري". وُلد بالقاهرة سنة خمس وأربعين وسبعمائة، ولم يكد يجاوز سن الحداثة حتى انتظم في حلقات الدروس، وتفقه بمذهب الشافعي، وحفظ كتاب "المنهاج في الفروع" للإمام النووي، وصار يعرف بالمنهاج نسبة إلى هذا الكتاب. وجمع بين آداب الطريقة وعلوم الشرع. تولَّى من المناصب

(8) هو علي بن محمد بن علي، المعروف بالشريف الجرجاني: فيلسوف. من كبار العلماء بالعبية. وله نحو خمسين

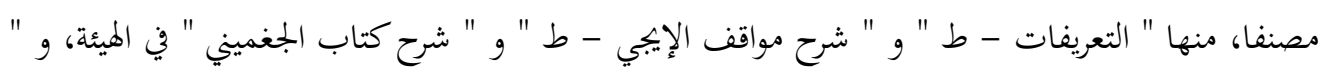

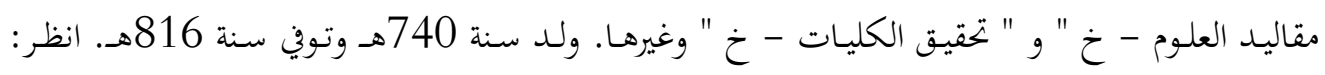

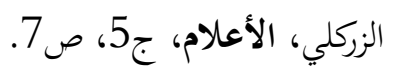

(9) هو علي بن حمزة بن عبد الله الأسدي بالولاء، الكوفي، أبو الحسن الكسائي: إمام في اللغة والنحو والقراءة. من الكن

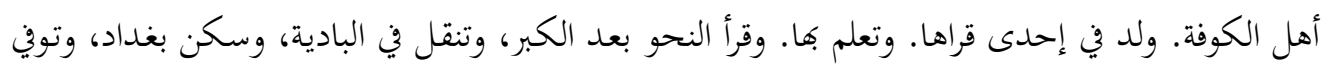

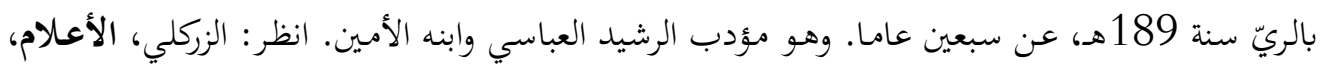

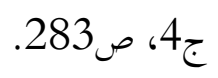

(10) هو يهيى بن زياد بن عبد الله بن منظور الديلميّ، مولى بني أسد (أو بني منقر) أبوزكرياء، المعروف بالفراء: إمام

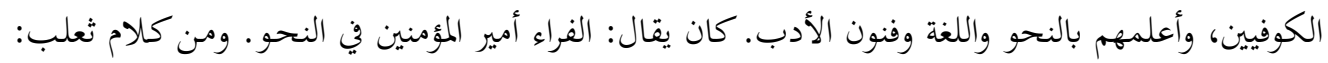

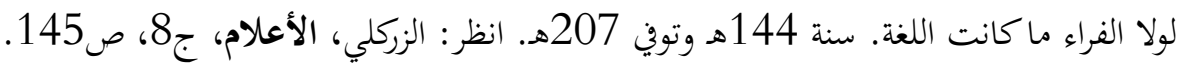


خانقاه كريم الدين بالقرافة الصغرى. وأقام في القسطنطينية. وتوفي بمر في رجب سنة أربع وتسعين وسبعمائة، ودفن بالقرافة بالقرب من تربة بكتمر الساقي (11).

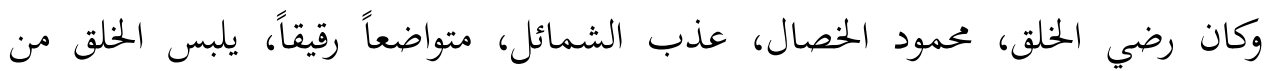
الثياب، ويرضى بالقليل من الزاد، لا يشغله عن العلم شيء من مطالب الدنيا، أو شؤون الحياة. ومن مؤلفاته: "تفسير القرآن" و "شرح الفقه الأكبر"، و"شرح الأسماء الحسنى"، ورسائل كثيرة في ترني التصوف. وكان يكتب مصنفاته بنفسه، وخطه جدا قل من يحسن استخراجه، ولذا شاع في الكتب المنقولة عن خطه الغموض والإجهام والتحريف والتصحيف ولقي منه القراء والدارسون العناء الكثير (12).

\section{ثانياً: تعريف "البرهان في علوم القرآن"}

يُعد هذا الكتاب من أجمع الكتب في علوم القرآن وأوسعها وأفضلها ، فقد ضمن خلاصة ما وصل إليه من علم التفسير في أكثر الجوانب التي عني هما، فتناول التعريفَ بعلم التفسير وعلوم القرآن، ومعرفة أسباب النزول، ومعرفة المناسبات بين الآيات، ومعرفة الفواصل ورؤوس الآي، وجمع الوجوه والنظائر، وعلم المتشابه، والمبهمات، وأسرار الفواتح والسور وخواتمها، ومعرفة المكي والمدني،

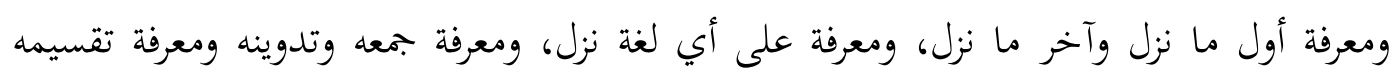

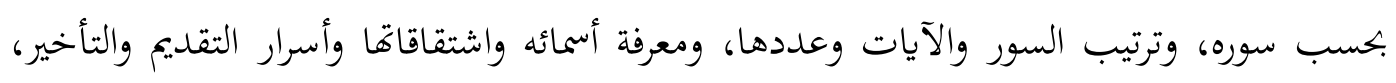
والتأكيد والمبالغة والحذف والإيجاز والإطناب والنكت البيانية والأنواع البديعية، والفروق في معاني المترادفات، وأسرار الكلمات التي ختمت بها الآيات إلى غير ذلك من النكت والأسرار. فجاء هذا الكتاب فريداً في بابه، جامعاً لصفوة آراء العلماء المحققين، وأقوال المتقدمين، يقول محقّق هذا الكتاب الأستاذ محمد أبو الفضل إبراهيم في مقدمة تحقيقه له منوّهاً بنبوغ المؤلف

$$
\begin{aligned}
& \text { (11) الزركشي، محمد بن همادر بن عبد الله، بدر الدين أبو عبد الله ، البرهان في علوم القرآن، تحقيق: محمد أبو }
\end{aligned}
$$

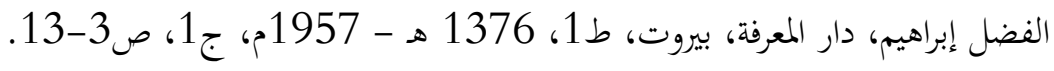

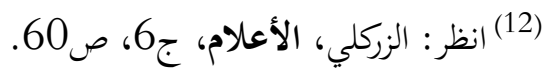


وفضله وسعة علمه كما يشيد بالكتاب: "كتاب البرهان في علوم القرآن الكريم وكتاب الله الخالد، قصره على سبعة وأربعين نوعاً كل نوع يدور حول موضوع خاص من علوم القرآن ومباحثه، يستأهل

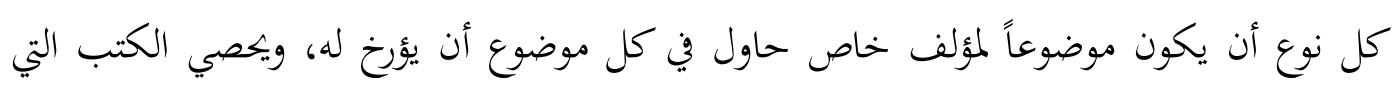

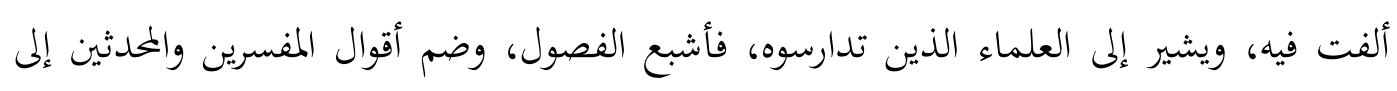
مباحث الفقهاء والأصوليين، إلى قضايا المتكلمين، وأصحاب الجدل، إلى مسائل العربية وآراء أرباب

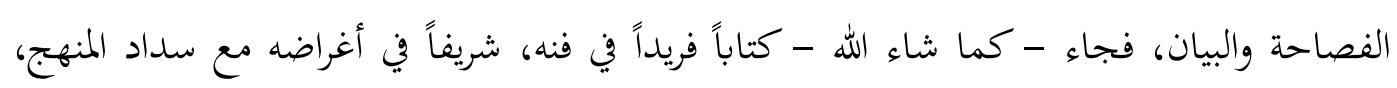
وعذوبة المورد، وغزارة المادة، بعيداً عن التعمية واللبس نائياً عن الحشو والفضول" (13).

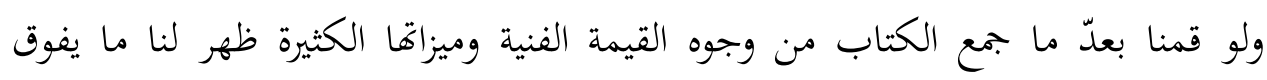
الإحصاء، ويتجاوز الاستقصاء، لكن يجدر بأن ألخِّص هنا بعض الجوانب القيمة التي جال فيها يراع المؤلف العبقري وأتى فيها بالعجب العجاب، فنذكر فيما يلي بعض السمات البارزة للكتاب.

\section{ثالثاً: العناية بالنواحي البلاغية في فهم أساليب اللغة}

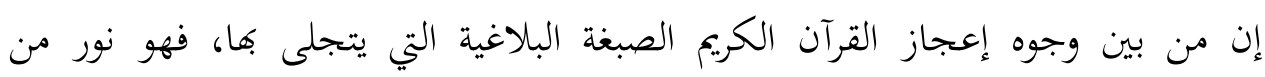

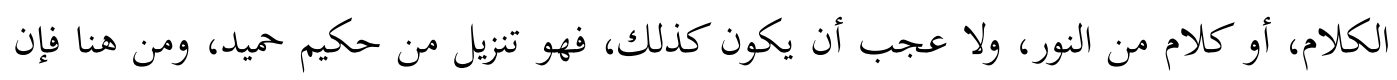
الإمام الفراهي الفاضل اهتم كثيراً بتجلية النواحي البلاغية في المباحث التي يستعرضها، أحياناً من قبل نفسه، وأحياناً كثيرة فيما ينقله عن الآخرين.

وحيث إن علم البلاغة يشتمل فنوناً ثلاثة وهي: علم المعاني وعلم البيان وعلم البديع، فإن الإمام الفراهي ظهر اهتمامه بكل ذلك وإليك بعض الأمثلة على ذلك: 1) علم البيان: لقد ذكر الإمام الفراهي ما يندرج تحت هذا من أنواع متعددة، وإليك بعضاً منها على سبيل المثال لا الحصر: الاستعارة، والمجاز، والكناية المرشحة، والتشبيه وأنواعه، والتورية والاستخدام والفرق بينهما، فقد فصل المؤلف القول في جميع هذه الأقسام البيانية،

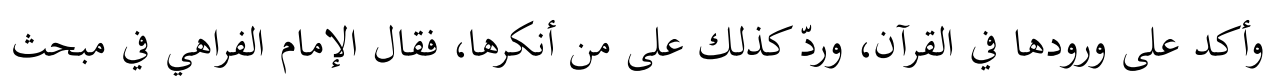

$$
\text { الزركشي، البرهان في علوم القرآن، ج1، ص1312 - (13) }
$$


الاستعارة: "هي من أنواع البلاغة، وهي كثيرة في القرآن، ومنهم من أنكره، بناءً على إنكار

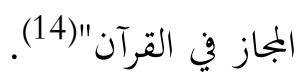

ثم يذكر الإمام الفراهي أمثلةً الاستعارة في القرآن وحقيقتها وحكمتها فيقول: "وحقيقتها أن تستعار الكلمة من شيء معروف بها إلى شيء لم يعرف بها، وحكمة ذلك إظهار الحنفي، وإيضاح الظاهر الذي ليس بجلي أو بحصول المبالغة أو للجموع.

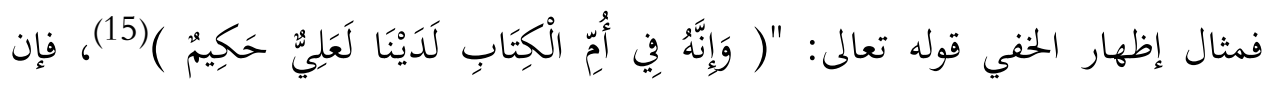

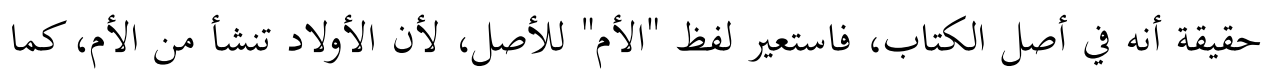

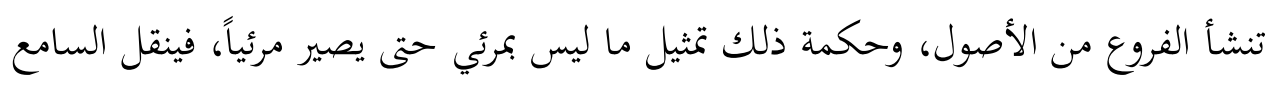

$$
\text { من حد السماع إلى حد العيان، وذلك أبلغ في البيان(16). }
$$

2) علم البديع: لقد حفل كتاب البرهان في علوم القرآن" بالأنواع الكثيرة التي يتضمنها هذا

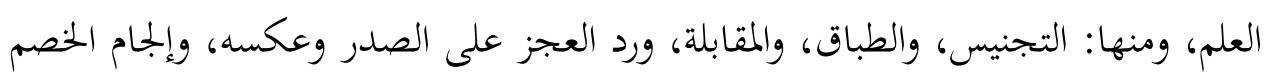
بالحجة، والتذييل. فبسط الإمام الفراهي الكلام في تعريفه، وأنواعه، بجانب ذكر الخلاف بين العلماء إن كان هناك، فانظر على سبيل المثال أنه ذكر التجنيس وأمثلته من القرآن ثم رد خلاف ابن أبي

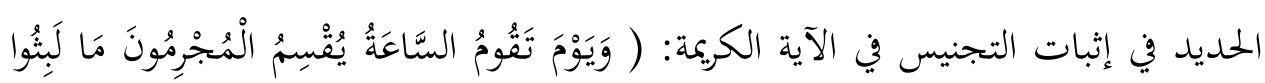

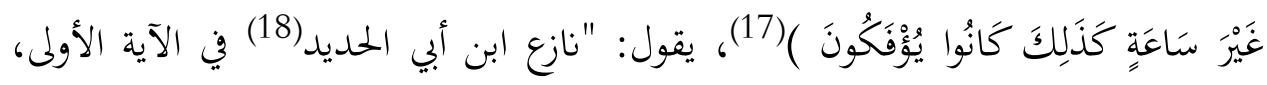

$$
\begin{aligned}
& \text { (14) الزكشي، البرهان في علوم القرآن، ج3، ص432 }
\end{aligned}
$$

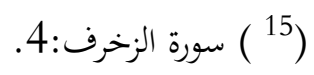

$$
\begin{aligned}
& \text { (16) الزركشي، البرهان في علوم القرآن، ج:3، صون } \\
& \text { (17) سورة الروم: الركي، الرهان في } 55 .
\end{aligned}
$$

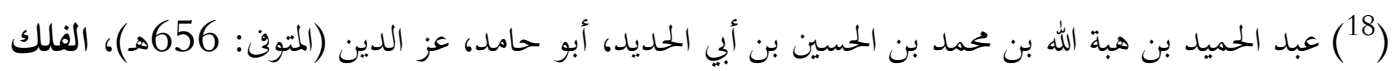

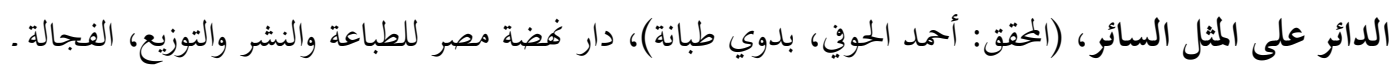

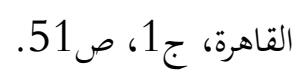


وقال: عندي أنه ليس بتجنيس أصلاً، وأن الساعة في الموضعين بمعنى واحد، والتجنيس أن يتفق اللفظ ويختلف المعنى، ولا تكون إحداهما حقيقة والأخرى مجازاً، بل تكونان حقيقتين، وإن زمان القيامة -وإن طال- لكنه عند الله تعالى في حكم الساعة الواحدة، لأن قدرته لا يعجزها أمر، ولا يطول عندها زمان، فيكون إطلاق لفظة الساعة على أحد الموضعين حقيقة وعلى الآخر مجازاً، وذلك يخرج الكلام من التجنيس، كما لو قلت ركبت حماراً،

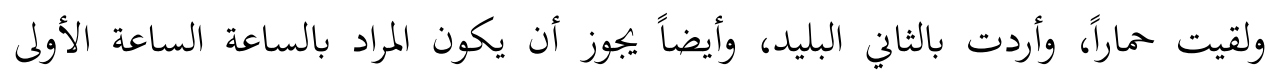

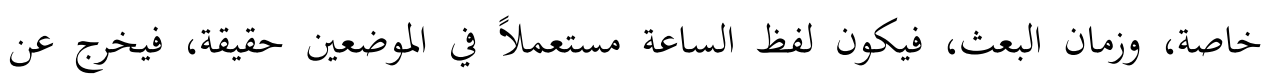
التجنيس. 3) الاستشهاد بالشعر: لم يكن خافياً على المؤلّف دور الشعر في فهم القرآن الكريم وتفسيره، وفي توضيح المعاني، لذلك ذكر المؤلف الشواهد الشعرية كما استشهد المؤلف بالشعر في قضية ورود البعض وإرادة الكل، يقول: "ويجوز أبو عبيدة ورود البعض وإرادة الكل، وخرج

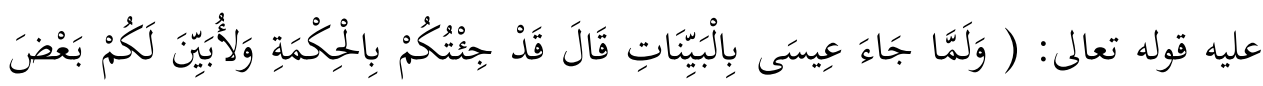

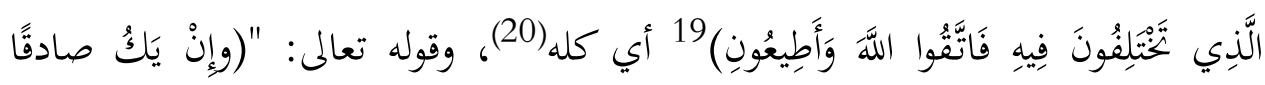

$$
\text { وأنشد بيت لبيد: يصبم بعض الذي يعدُكم)"(21). }
$$

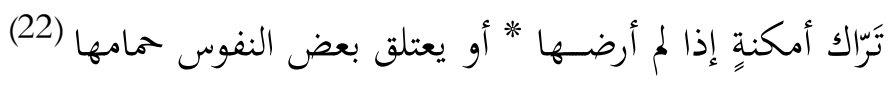

$$
\begin{aligned}
& \text { (19) سورة الزخرف: } 63 .
\end{aligned}
$$

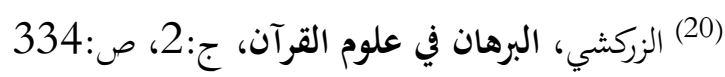

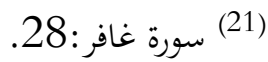

$$
\begin{aligned}
& \text { (22) الموسوعة الشعرية، معلقة لبيد بن ربيعة العامري، ج11، صواري، } 3 .
\end{aligned}
$$


المطلب الثالث: الموازنة بين "أساليب القرآن" للفراهي وبين "البرهان في علوم القرآن" للزركشي من خلال استعراض الكتابين، فإننا نجدهما مشتملين على مباحث مهمة وفوائد جليلة، بحيث يتوافق كلاهما على غاية شريفة وهدف نبيل، وهو خدمة القرآن الكريم، وتمهيد السبل للتوصل إلى ما يتضمنه من اللطائف والأسرار المكنونة، كما يهدف إلى توضيح الآيات وتفسير البينات، ونجد كذلك تباين منهج العرض والاستدلال والترتيب والاختلاف في المباحث القرآنية. الأول: فإن كتاب الفراهي كما سبق أن قلتُ إنه عبارة عن رسالة وجيزة تتحدث عن عموم أساليب كلام العرب، ويقصد إحاطة العلم بدلالات الصور والأساليب، ومواقع استعمالها، كما صرح بذلك الفراهي رحمه الله في بداية كتابه حيث قال: "كما أن المقصود من كتاب المفردات إحاطة العلم حتى

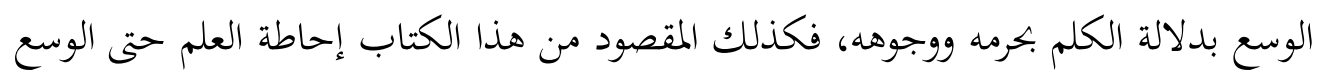
بدلالات الصور والأساليب ومواقع استعمالها"(23). أما كتاب الزركشي فهو بمثابة الأمهات للكتب المؤلفة في الدراسات القرآنية، ومن ميزاته البارزة: الجمع والاستيعاب والشمول، مع أجود الترتيب والتبويب، وهو في أربعة مجلدات ضخمة يجمع ما قاله الأئمة الأعلام في هذا الفن سواء كانوا مفسرين أم محدثين أم أصوليين أم لغويين أم بلاغيين، فيبدو الزركشي في كتابه كأنه يتوخى من خلال كتابه التعرض لجميع المباحث القرآنية

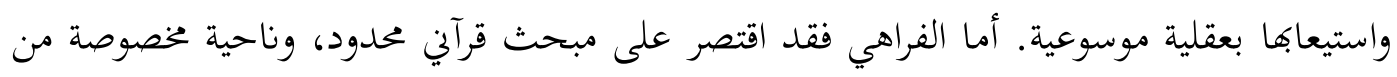

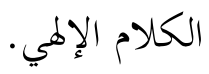
الثاني: تصدى كلا الكتابين للمباحث القرآنية والأساليب البيانية من أسلوب الخطاب والالثفات، ومواقع الحذف والعود على البدأ، والوصل والفصل والتذييل، إلا إذا أمعنا النظر بين الكتابين نجد أن الفراهي أقدر من الزركشي على تفسير مكنونات صدره وإثبات رأيه بكثير، كما أن الفراهي يمتاز أيضاً عن الزركشي في الإتيان بنكت شريفة ولطائف دقيقة، والتي لم أجدها عند الزركشي في "البرهان"، انظر في هذا المقال: "مبحث القرآن والوصل"، والفرق بينهما في كتابه الأساليب، وهو

$$
\text { (23) (الفراهي، أساليب القرآن: ص9. }
$$

Mohd Farid Ravi Abdullah, Abur Hamdi Usman, أساليب القرآن للفراهي... 
يدل على عقلية الفراهي المبتكرة، وطبيعته المخترعة المتوقدة، أما الزركشي فهو يقتصر على الاهتمام بنقل الآراء عن الآخرين أكثر من الاهتمام بالاختراع والابتكار.

الثالث: نجد ذكر مبحث الالتفات في الكتابين كليهما بغاية من الإسهاب والتفصيل فقد توسَّع المؤلفان كلاهما في بسط الحديث عن الالتفات وتقديم الأمثلة والأدلة من كالام العرب الأولين، وأساليب بياهم، إلا أن الفراهي يتفوق على الزركشي بذكر الفوائد والحكم الخفية من مجيء الالتفات في القرآن الكريم، يقول الفراهي وهو يذكر فوائد الالتفات: "اعلم أن الالتفات في القرآن كثير جداً في كلام العرب، ومن فوائده العامة: انتباه السامع، ومنها إحضار البعيد، ومنها شدة الخطاب، ومنها صرف التوجه عن السامع تصغيراً له وإعراضاً عنه، ومنها صرف الخطاب الشديد إلى أكبرهم، ومنها التعريض بكن يتوقع منه الإنكار أو الكراهية، والالتفات من مخاطب إلى مخاطب، والالتفات لتنويع المعنى والالتفات لإرادة التوبيخ"(24). هذه بعض أهمّ جهود الإمام الفراهي في مجال الدراسات القرآنية، وقد خصصت في هذا الفصل بما كان يتعلق منها بعلوم القرآن فقط، حتى أقوم بالموازنة بين كتب الفراهي فيها وبين ما كتبه فيها المؤلِّفون السابقون، مع إبراز خصائص مناهج كل منهم في كتبهم.

الخاتمة

1. إن الإمام الفراهي هو من العلماء القلائل في الهند، الذين جمعوا بين الثقافتين الإسلامية والغربية، ولذلك كانت شخصيته مرجعاً كبيراً لكثير من المثقَّفين المسلمين من عُلية القوم. 2. إن الإمام الفراهي عرف في طيلة حياته، بفرط الذكاء، ونفاذ البصر، وسرعة الإدراك، ودقة الاستباط، وغزارة العلم، وسعة الاطلاع، فكان عالماً ذا ثقافة واسعة متنوِعة. 3. إن منهج الإمام الفراهي في مؤلفاته يختلف عن منهج عامة المؤلفين الذين إذا عزموا على تأليف كتابٍ جمعوا في أول وهلةٍ مادةً موضوعه، ثم رتَّوها في صورة كتابٍ. أما الإمام الفراهي فله مذهب خاص به، وأنه إذا شعر بحاجةٍ إلى الكتابة أو التأليف في موضوع ما، أو حلّ

$$
\text { (24) الفراهي، أساليب القرءان، ص170. }
$$


مشكلة من المشكلات في مسألة علمية؛ فكانت الموضوعات في ذلك الموضوع تتمثَّل بين عينيه. وهو يُديم النظرَ والبحث فيها، فإذا حقَّق مسألةً، أو حلَّ معضلةً، أو أحكم رأياً؛ قيَّد ذلك وكتب عليه: "من كتاب ..."، حتى إذا اكتملت جوانب البحث أقبل على تأليفها وتنسيقها، لذلك كان يؤلّف كتباً عديدةً في وقت واحد، ولهذا السبب بقي أكثرُ مؤلفاته

4. أنه لا يكرِر في مؤلَّفاته ما قاله الآخرون دون الوقوف عندها وقفات في غاية الحسن والنفع. 5. إن أسلوب الإمام الفراهي في مؤلَّفاته كان يتسم بالجرأة والثقة بالنفس في مناقشة المسائل. إن الإمام الفراهي بدراسته العميقة لللغة العربية وأداهما وعلومها قد صار عربيا في التعبير والتحبير وصار ذوقه الأدبي كالعرب الخلص. ولكن مع كل هذه المزايا التي بتحست في شخصيته كانت مزية أخرى قد تغلبت تلك المزايا كلها وهي حب القرآن الكريم فوق كل شيء. ولن يشعر بعظمة هذا القرآن إلا من كان عربيًا خالصًا.

المراجع و المصادر

Al-'Āmirī, A. A. (2004). Dīwān labīd ibn Rabī‘ah al-'Āmirī. Beirut: Dar al-Ma'rifah.

Al-Farāhī, A. H. (1992). Majmū 'ah Tafâsīr Farāhī. Lahore, Pakistan: Paran Foundation.

Al-Farāhī, A. H. (1994). Im ‘ān fì Aqsām al-Qur'ān. India: al-Da'irah al-Hamidiyah.

Al-Farāhī, A. H. (2011). Asā İ̉b al-Qur'ān. India: al-Da'irah alHamidiyah.

Al-Iṣlāḥī, A. (2009). Muqaddimah Tadabbur al-Qur'ān. Lahore, Pakistan: Paran Foundation.

Al-Iṣlāḥī, S. (2001). Rā 'id al-Fikr al-Ișlāḥī. New Delhi, India: Balagh Publication.

Al-Muznī, Z. A. (1988). Dīwān Zahīr ibn Abī Salmī. Beirut: Dar alKutub al-'Ilmiyyah. 
NUKHBATUL 'ULUM : Jurnal Bidang Kajian Islam

Vol. 6, No. 2 (2020) : Hal. 258-272

Website: https://journal.stiba.ac.id

ISSN : 2685-7537 (online); 2338-5251 (Printed)

Al-Zarkashī, B. M. (1957). Al-Burhān Fì 'Ulūm al-Qur'ān. Beirut: Dar al-Ma'rifah.

Al-Zirkilī, K. M. (2002). Al-A 'lām. Beirut: Dar al-'Ilm li al-Malāyīn. 